\title{
The formation of calcium phosphate coatings by pulse laser deposition on the surface of polymeric ferroelectric
}

\author{
E.N. Bolbasov ${ }^{1}$, I.N. Lapin², V.A. Svetlichnyi ${ }^{2}$, Y. Lenivtseva $^{1}$, A. Malashicheva ${ }^{3,4,5}$, Y. \\ Malashichev $^{4}$, A. Golovkin ${ }^{3}$, Y.G. Anissimov ${ }^{6}$, S.I. Tverdokhlebov ${ }^{1}$
}

1. Tomsk Polytechnic University, 30 Lenin Avenue, Tomsk 634050, Russian Federation.

2. Tomsk State University, 36, Lenin Avenue, Tomsk, 634050, Russian Federation.

3. Federal Almazov Medical Research Centre, Akkuratova, 2, 197341, St. Petersburg, Russian Federation.

4. St. Petersburg State University, Universitetskaya nab., 7/9, 199034, St. Petersburg, Russian Federation.

5. ITMO University, Institute of translational Medicine, St. Petersburg, Russia

6. Griffith University, School of Natural Sciences, Engineering Dr., Southport, QLD 4222, Australia.

Corresponding author: Sergei I. Tverdokhlebov, e-mail: tverd@tpu.ru, phone: +7(3822)5634-37, Tomsk Polytechnic University, 30 Lenin Avenue, Tomsk 634050, Russian Federation

\begin{abstract}
This work analyses the properties of calcium phosphate coatings obtained by pulsed laser deposition on the surface of the ferroelectric polymer material. Atomic force and scanning electron microscopy studies demonstrate that, regardless of the type of sputtering target, the calcium phosphate coatings have a multiscale rough surface that is potentially capable of promoting the attachment and proliferation of osteoblasts. This developed surface of the coatings is due to its formation mainly from a liquid phase. The chemical and crystalline 1
\end{abstract}


composition of the coatings depends on the type of sputtering target used. It was shown that, regardless of the type of sputtering target, the crystalline structure of the ferroelectric polymer material does not change. Cell viability and adhesion studies of mesenchymal stromal cells on the coatings were conducted using flow cytometry and fluorescent microscopy. These studies indicated that the produced coatings are non-toxic.

Keywords: calcium phosphate coatings, copolymer of Vinilidene Fluoride and Tetrafluoroethylene, pulse laser deposition, hydroxyapatite, monetite.

\section{Introduction}

Implants made from fluoropolymers are ubiquitous in modern medicine [1]. Such implants are used in ophthalmology [2,3] vascular surgery [4], surgery [5], orthopedics [6], traumatology [7] and tissue engineering [8,9]. The widespread use of fluoropolymers in medicine is due to their beneficial properties, such as: high chemical resistance, good mechanical properties, heat resistance, thermal stability and biological inertness $[10,11]$. Some fluoropolymers, such as polyvinylidene fluoride (PVDF), vinylidene fluoride with tetrafluoroethylene copolymer (VDF-TeFE) and vinylidene fluoride copolymer with trifluoroethylene (VDF-TrFE) have piezoelectric and ferroelectric properties [12].

Piezoelectric and ferroelectric properties of these polymer materials arise from strong dipole moment of perpendicular polymer chain occurring at the specific conformation of the macromolecule. A significant dipole moment arises due to the higher electronegativity of fluorine atoms in comparison with hydrogen and carbon ones [13]. There are three main crystalline modifications of the polymers $(\alpha, \beta, \gamma)$ that are differing in chain conformation. The $\alpha$ - modification is characterized by a monoclinic lattice in which the chain conformation (TGTG-) has opposite dipole moments, so in general it is non-polar. The $\beta$ - modification has an orthorhombic lattice with a polar cell in which chains have a planar zigzag conformation. The $\gamma$ - modification is comprised of a polar cell with the chain conformation $T_{3} G T_{3} G^{-}$. In 
addition the $\beta$-modification is the most electrically active phase as it has the most significant dipole moment $\left(\approx 8 \times 10^{-30} \mathrm{Cm}\right)[14]$.

The ferroelectric property of PVDF or its copolymers gives the opportunity to actively influence the pool of biological cells placed on its surface. It has been demonstrated that an increase in the ferroelectric $\beta$ phase stimulates the differentiation of mesenchymal stem cells (MSC) in osteoblasts $[15,16]$ and accelerates the regeneration of bone tissue $[17,18]$ and stimulates attachment of neurons [19,20]. Devices made using polymeric ferroelectric materials were previously used for mechanical stimulation of osteoblasts [21,22].

It is known that the processing conditions of PVDF and copolymers (the rate of crystallization from the melt or solution, orientation drawing, annealing, hardening, etc.) significantly affect its crystal structure and hence the physical characteristics of the formed product [13].

The main disadvantage of implants made of PVDF and its copolymers is a limited capacity for integration within tissues due to its low surface free energy. To overcome this shortcoming a series of studies on the surface modification of fluoropolymers was conducted in different research centers to improve the integration of the implants into the surrounding tissues [23-25] For applications associated with the regeneration of bone tissue on the surface of fluoropolymers calcium phosphate coatings (CaP) are applied, usually by RF magnetron sputtering [26,27]. It is known that CaP coatings have a high biological compatibility and promote the attachment and proliferation of osteoblasts on their surface. It is desirable for biocompatibility that the surface of coatings is multiscale rough, and the coating structure has considerable number of macro- and micro-pores [28]. However, the RF magnetron sputtering CaP coatings usually do not have the multiscale rough surface [29,30], which has the potential to reduce the degree of integration with the surrounding tissues. During the coating formation 
by RF magnetron sputtering there is a substantial heating of the coated sample. For the case of coating PVDF and its copolymers this heating is capable of causing an undesirable change in the polymer's crystal structure [31].

Thus, to provide the possibility of additional osteoblasts stimulation, the ferroelectric polymer materials should have a rough biocompatible calcium phosphate coating. At the same time the process of calcium phosphate coating formation should not affect the polymer conformational structure to avoid the transformation of $\beta$ phase to $\alpha$ phase in order to preserve the crystal structure of the polymer material with ferroelectric properties.

One of the promising ways to create $\mathrm{CaP}$ coating on the surface of ferroelectric polymer materials satisfying the above requirements is a method of pulse laser deposition (PLD) [32]. PLD method is based on a laser ablation of target due to powerful laser pulses in a vacuum or in the presence of a background gas. As a result of a rapid local heating of the target material a plasma plume is formed, which spreads in a vacuum or a rarefied gas and is deposited on the surface of the substrate, forming a thin film. The properties of the film depend on the parameters of radiation, the material of the target and the coated substrate [33]. The selection of the experimental conditions aims to minimize the impact of the process on the properties of the substrate material. PLD method using hydroxyapatite $\left(\mathrm{Ca}_{10}\left(\mathrm{PO}_{4}\right)_{6}(\mathrm{OH})_{2}\right.$, HAP) target is widely used for the creation of biocompatible CaP coatings on surfaces of metal, ceramic and polymeric materials $[34,35]$. Another promising target compound for the formation of CaP coatings is Dicalcium Phosphate Anhydrous $\left(\mathrm{CaHPO}_{4}\right.$, DCPA) [36,37]. Hitherto there is no literature data on obtaining CaP coatings by PLD using DCPA targets. The influence of the formation of coatings by PLD on the crystal structure of ferroelectric polymer substrates is poorly understood, which restricts further development of the technology. 
Thus, the main objectives of our work were: to investigate the possibility of formation of CaP coatings by PLD on the surface of the ferroelectric polymer material and to study the properties of the coatings and their dependence on the sputtering target material. Impact of the formation of coatings on the crystal structure of the ferroelectric polymer substrate materials was also investigated.

\section{Materials and methods}

Formation of the polymer film on plates was performed as described in [38]. In this work two types of plates were used: stainless steel (321 stainless steel, dimensions of $20 \times 20 \mathrm{~mm}$ ) and glass (microscope slide, dimensions of $20 \times 40 \mathrm{~mm}$ ). The CaP coatings were formed using PLD method on the surface of the ferroelectric polymer films. The fundamental harmonic of a repetitively pulsed solid-state Nd:YAG laser (Lotis TII, Belarus) was used with wavelength of $1064 \mathrm{~nm}$, pulse energy $170 \mathrm{~mJ}$, pulse duration $7 \mathrm{~ns}$ and pulse repetition frequency of $15 \mathrm{~Hz}$. The radiation was focused onto the target surface by a spherical lens with a focal length of $250 \mathrm{~mm}$ and spot diameter of $2 \mathrm{~mm}$. Maximum pulse power and energy density on the target surface were $0.75 \mathrm{GW} / \mathrm{cm}^{2}$ and $5 \mathrm{~J} / \mathrm{cm}^{2}$, respectively. Distance from an ablation point on the target to the substrate was $3 \mathrm{~mm}$. The working vacuum chamber, where the target and substrate were placed, had the diameter of $70 \mathrm{~mm}$ and the height of 40 $\mathrm{mm}$ (volume $\mathrm{V} \sim 150 \mathrm{~cm}^{3}$ ). The vacuum in the chamber was created by a rotary vane pump HP-2 and the residual pressure was less than $1 \mathrm{~Pa}$. The target, consisting of the pressed powders of analytical grade HAP or DCPA, had a cylindrical shape with the diameter of 16 $\mathrm{mm}$ and the height of $5 \mathrm{~mm}$. The compression of the powder was performed in a hydraulic press T-40 (SPECAC, UK) with a nominal pressure of 20 tons.

Investigation of the surface morphology of the resulting coatings was performed using scanning electron microscopy (SEM, ESEM Quanta 400, FEG). A thin layer of gold was 
applied to the surface of the investigated sample for 60 seconds using a magnetron sputtering system SC7640 (Quorum Technologies Ltd).

Morphological characteristics of the coatings (e.g. particle size), were measured using the software Image J 1.38 (National Institutes of Health, USA).

Surface properties were also studied using the high resolution atomic force microscopy (AFM) using Solver-HV (NT-MDT). The topology and surface potential of the coatings were determined by the method described previously [39].

The study of the elemental composition of the samples was performed by X-ray fluorescence analysis (XRF) using X-Ray Fluorescence Spectrometer (Shimadzu XRF 1800) with the accelerating voltage of $40 \mathrm{kV}$, current $95 \mathrm{~mA}$, scanning speed $8^{\circ} / \mathrm{min}$ and the scanning step $0.1^{\circ}$.

Examination of the chemical structure of the samples was performed for the films obtained on the glass substrate. For this purpose, the film was mechanically separated from the plate. The result was a sample on one side of which was the CaP coating. Both sides of the sample were investigated using the method of Attenuated Total Reflectance (ATR) Fourier Transform Infrared spectroscopy (FTIR). Spectrometer Tensort 27 (Bruker) with ATR attachment (PIKE MIRacle, with the angle of incidence $45^{\circ}$ ) on the crystal ZnSe was used. Investigations were carried out in the spectral range of 500 to $2000 \mathrm{~cm}^{-1}$ with a resolution of 4 $\mathrm{cm}^{-1}$.

The crystal structure of the samples was investigated using X-ray diffraction analysis with Shimadzu XRD 6000 diffractometer. The samples were exposed to a monochromatic $\mathrm{Cu}$ K-alpha (1.54056 $\AA$ ) radiation. The accelerating voltage and the beam current were set to 40 $\mathrm{kV}$ and $30 \mathrm{~mA}$ respectively. The scanning angle range, scanning step size and signal collection time were $6-55^{\circ}, 0.0200^{\circ}$ and 1.5 seconds respectively. As references we used the 
following entries from the PDF - 4 database: Hydroxyapatite (\#00-055-0592) and Dicalcium Phosphate Anhydrous (\#01-071-1759). The average size of the crystals $\left(l_{c}\right)$ was evaluated using the Debye-Scherrer equation:

$$
l_{c}=\frac{k \lambda}{\cos \theta \sqrt{\beta^{2}-\beta_{r}^{2}}},
$$

where $\lambda$ is the wavelength of the incident radiation, $\beta$ the width of the reflection at half height, $\beta_{r}$ is the broadening reflex of the apparatus, $\theta$ is the angle of diffraction and $k=0.9$.

Evaluations of the effectiveness of cell adhesion to the modified surface were conducted by fluorescent microscopy using universal stereoscopic complex Leica M205 FA (Research Resource Centre "Molecular and Cell Technologies", Saint-Petersburg State University; www.biomed.spbu.ru/en/). The effectiveness of cell adhesion was assessed by the number of adherent cells visible in ten fields of view of the microscope with the average normalised for $1 \mathrm{~mm}^{2}$.

To estimate the cell adhesion multipotent mesenchymal stromal cells (MSC) derived from adipose tissue from healthy donors were used. Before culturing cells by flow cytometry (Guava Easy Cyte 6, Millipore, USA), a phenotypic analysis of these cells was performed using monoclonal antibodies CD19, CD34, CD45, CD73, CD90 and CD105 (BD, USA) as previously described [40]. The study was performed according to Helsinki declaration and approval was obtained from the local Ethics Committees in Almazov Federal Medical Research Centre. Written informed consent was obtained from all subjects prior to the fat tissue biopsy. The cells culturing was performed on titanium discs with a diameter of $10 \mathrm{~mm}$, one side of which was coated with the test coating. The test samples were placed in the wells of 24-well culture plate. The cells were plated on the samples at a concentration of $10 \times 10^{3}$ / $\mathrm{cm}^{2}$ and cultured for 72 hours. 
The cells were maintained in alpha-MEM medium (PanEco, Russia) supplemented with $10 \%$ fetal calf serum (Hyclone, USA), 50 units $/ \mathrm{mL}$ penicillin and $50 \mu \mathrm{g} / \mathrm{mL}$ streptomycin (Invitrogen, USA) at $37^{\circ} \mathrm{C}$ and $5 \% \mathrm{CO}_{2}$. As a control the cells without the specimens were used.

To visualize the cells the specimens MSC were infected with the lentivirus bearing GFP, seeded onto specimens and after $72 \mathrm{~h}$ fixed with cold methanol for $5 \mathrm{~min}$ at room temperature, cell nuclei were stained with DAPI. Lentivirus production was as followes: the pLVTHM (20 $\mu \mathrm{g})$, pMD2G (5 $\mu \mathrm{g})$, and packaging pCMV-dR8.74psPAX2 (5 $\mu \mathrm{g})$ plasmids were co-transfected into HEK-293T cells by a calcium phosphate method. The resultant production of lentivirus was concentrated by an ultracentrifugation method, resuspended in PBS with 1\% BSA, frozen in aliquots at $-80^{\circ}$ and tittered using HEK-293T cells as described previously [41].

The study of the viability of cells on the modified surface was carried out by flow cytometry using Guava Easy Cyte 6 (Millipore, USA). For this purpose the cells were detached from the surface of the films with $0.5 \%$ solution of trypsin-EDTA (Sigma Aldrich, USA), centrifuged $10 \mathrm{~min}$ at $716 \mathrm{~g}$, resuspended in $1 \mathrm{ml}$ of culture medium and stained with Annexin V-FITC Apoptosis Detection kit (Sigma Aldrich, USA) with detection Annexin VPropidium Iodid- (live), Annexin V+ Propidium Iodid+ (necrotic) and Annexin V+ Propidium Iodid- (apoptosis).

The data were analysed using the methods of statistical description and statistical hypothesis testing available in the standard software package Statistica (version 6.0). For the analysis of the data the hypothesis of normal distribution (Kolmogorov-Smirnov test) was used. In the case of the normal distribution the statistical significance was assessed using the Student's t-test. For non-normal distribution the statistical significance was determined by 
nonparametric tests. To assess the significance of differences in three indicators within the same group the Friedman test was used. For the pairwise comparisons Wilcoxon test with Bonferroni correction was used. Data were presented as median and quartiles 25 and 75 (Me (25\%; 75\%)). For all types of statistical analysis significance level was 95\% ( $<<0.05)$.

\section{Results and discussion}

The SEM image of calcium phosphate coatings surface obtained by PLD from HAP target is shown on Fig. 1. Macro accumulations with an average size of $9.7 \pm 3.8 \mu \mathrm{m}$ were observed on the surface of obtained coating with a slight magnification (larger scale, Fig. 1a).

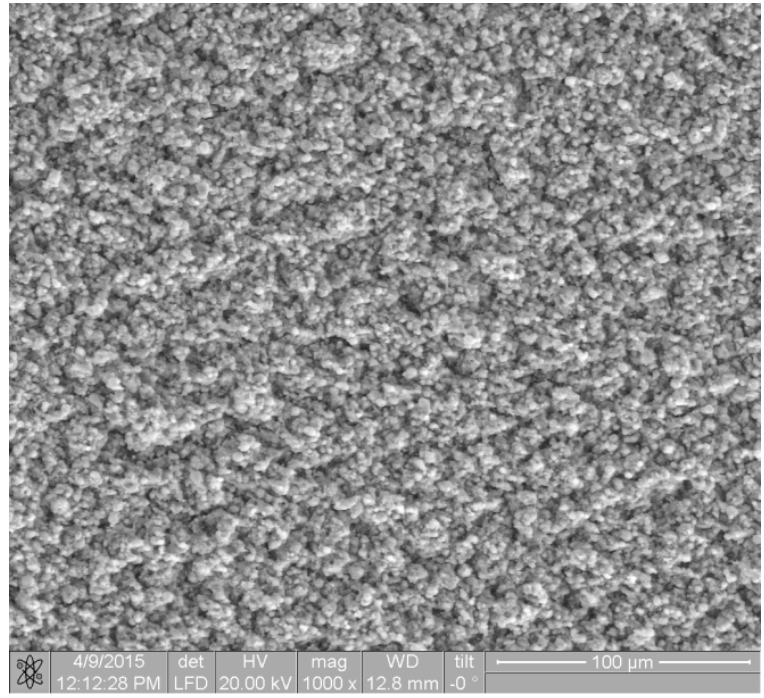

a

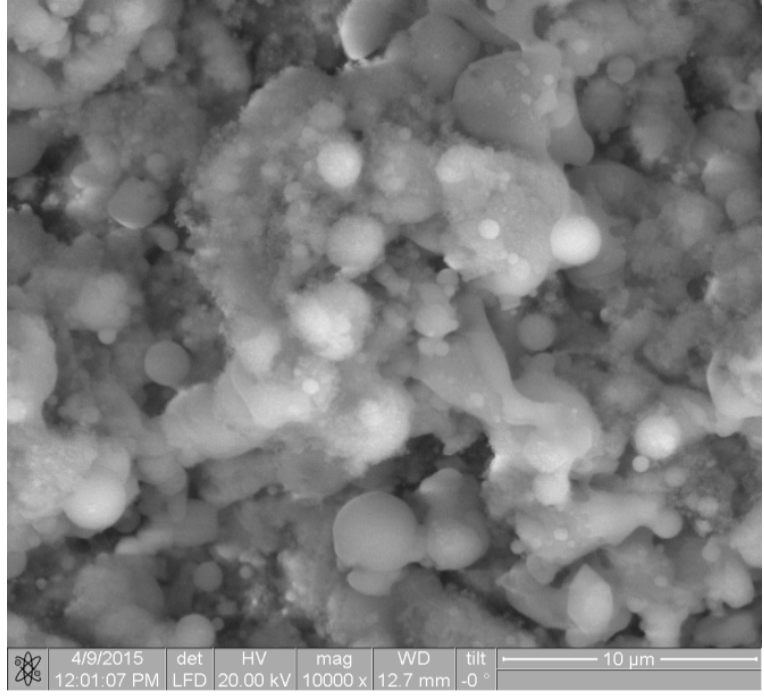

b

Fig. 1. SEM images of coating derived from PLD with HAP target.

At high magnification (Fig. 1b) it was established that microstructure of macro accumulations is formed by round-shape particles with an average size of $2.5 \pm 1.2 \mu \mathrm{m}$.

The SEM image of calcium phosphate coatings surface obtained by PLD from DCPA target is shown on Fig. 2. In Fig. 2a macro accumulations were also observed on the surface 
of obtained coating with their average size of $16.5 \pm 10.3 \mu \mathrm{m}$. The size is therefore larger than that found on coatings obtained from the HAP target.

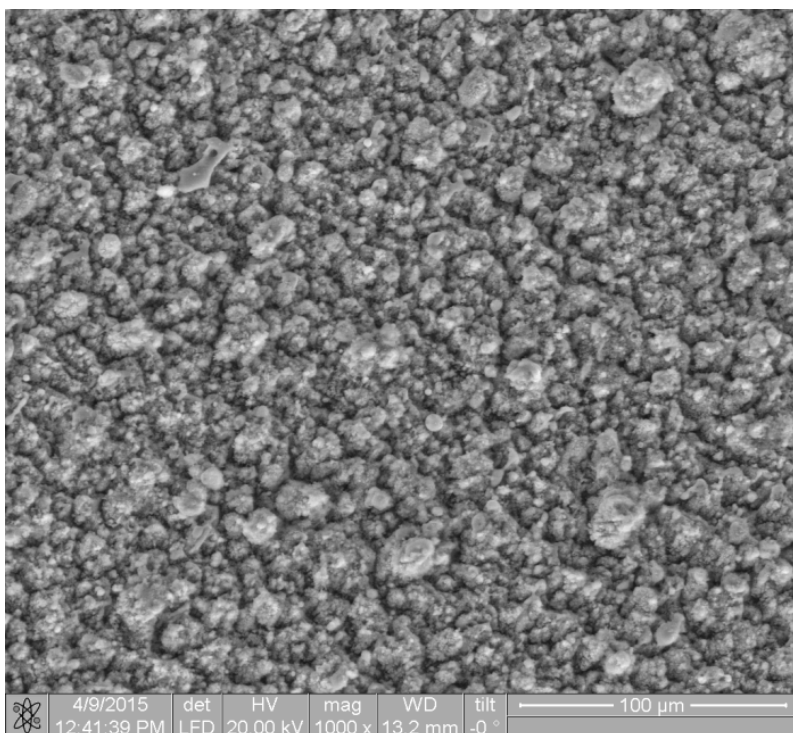

a

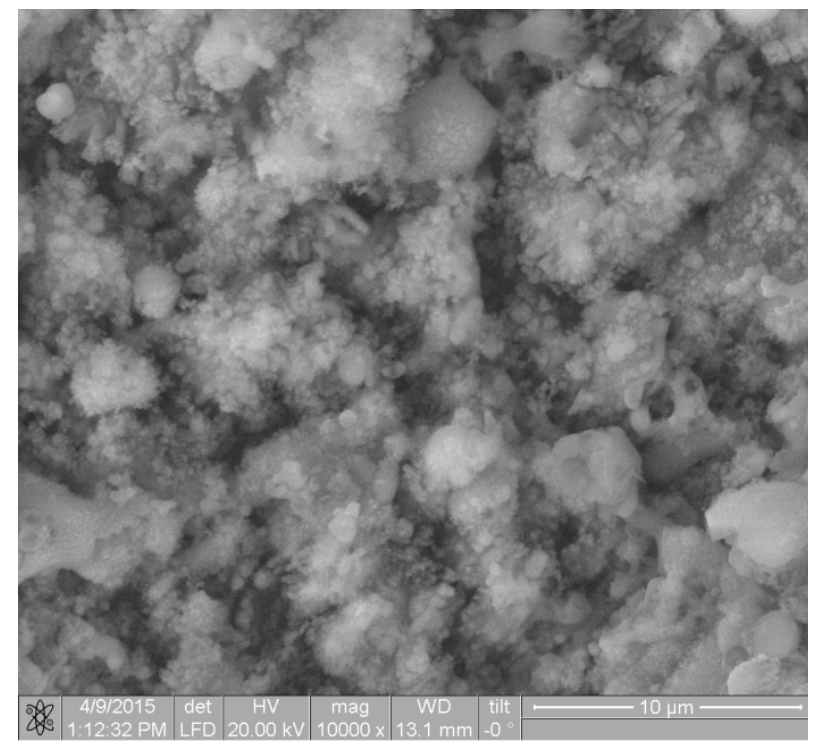

b

Fig. 2. SEM images of coatings derived from PLD with DCPA target.

As in the case of HAP target microstructure of macro accumulations are formed by round-shape particles with the average size of $2.3 \pm 0.9 \mu \mathrm{m}$ (Fig. 2b).

The high resolution AFM topography imaging of the samples (Fig. 3 a, c, e) demonstrated that the micro particles have their own rough surface topography. For HAP target the micro particles are formed by predominantly spherical particles of $0.25 \pm 0.14 \mu \mathrm{m}$ diameter. For DCPA target the micro particles are formed by two types of particles: spherical particles of $0.21 \pm 0.11 \mu \mathrm{m}$ diameter and more elongated particles with average length of 0.33 $\pm 0.11 \mu \mathrm{m}$.

Hence, the research results obtained using SEM and AFM techniques demonstrated that a complex multiscale roughness structure of a coating surface is formed under the selected conditions of coating formation for both types of the sputtering target. It should be noted that a similar structure of the coatings was previously noted in $[42,43]$. This is 10 
consistent with current physical models of PLD, as during the nanosecond laser ablation the gas plasma cloud is composed of ions and large clusters, which can be further integrated due to intense collisions during the motion of the plasma cloud from the target to the substrate [32], [44].

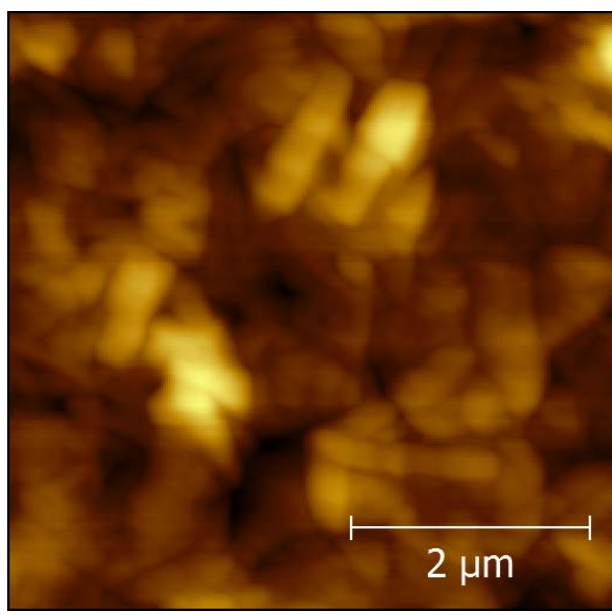

a

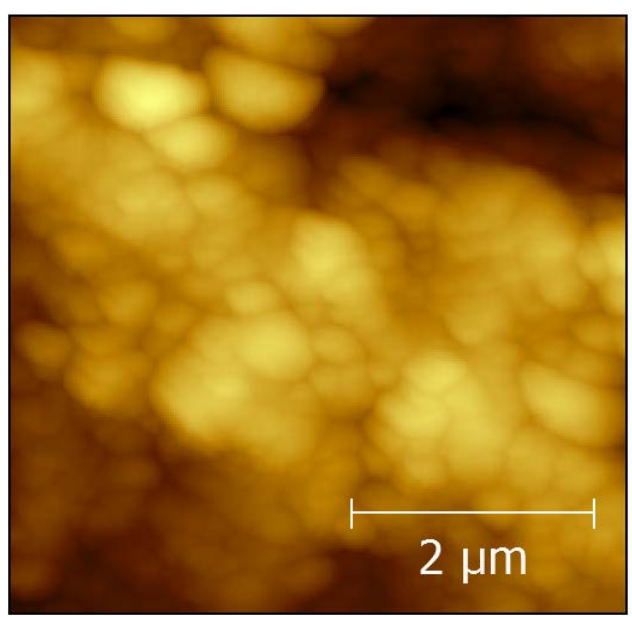

C
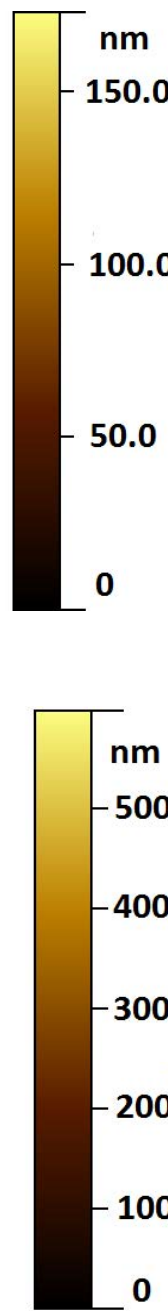

0
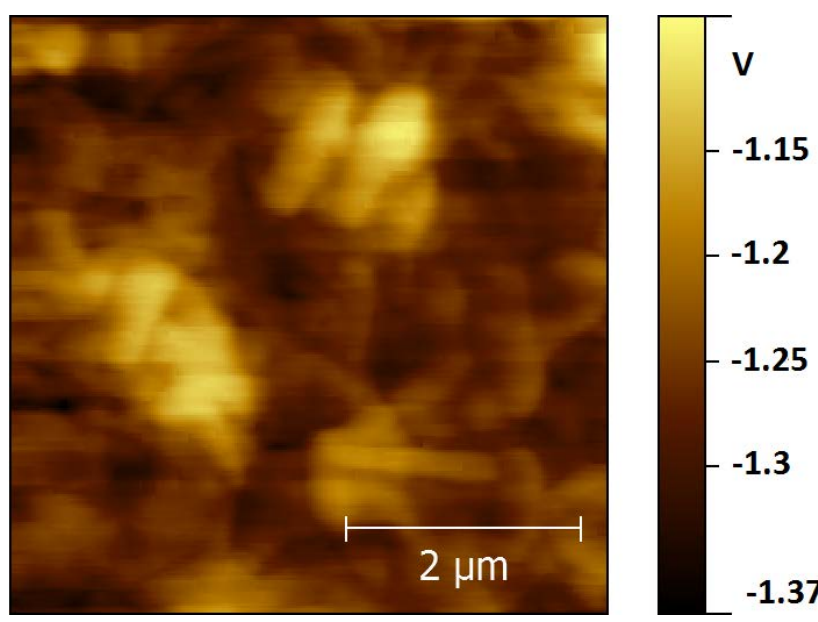

$\mathrm{b}$
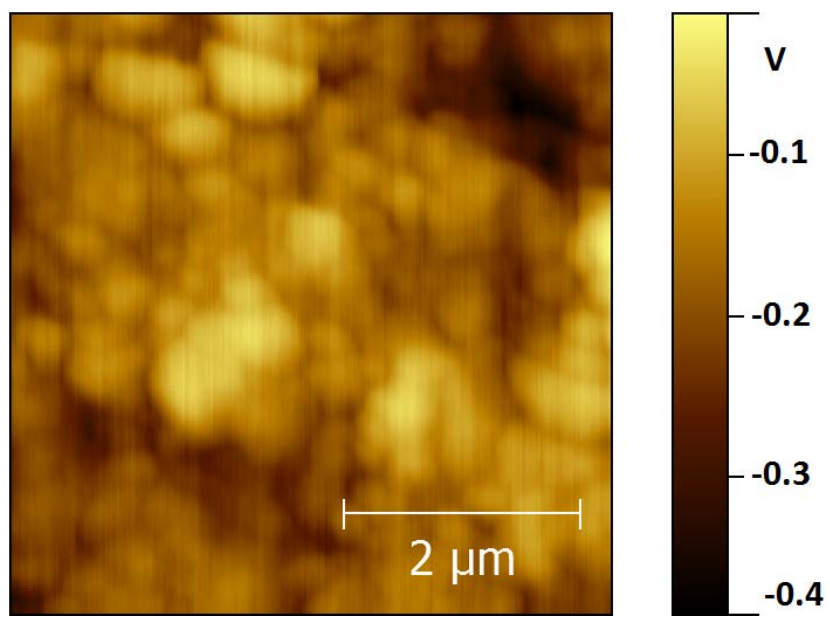

d 


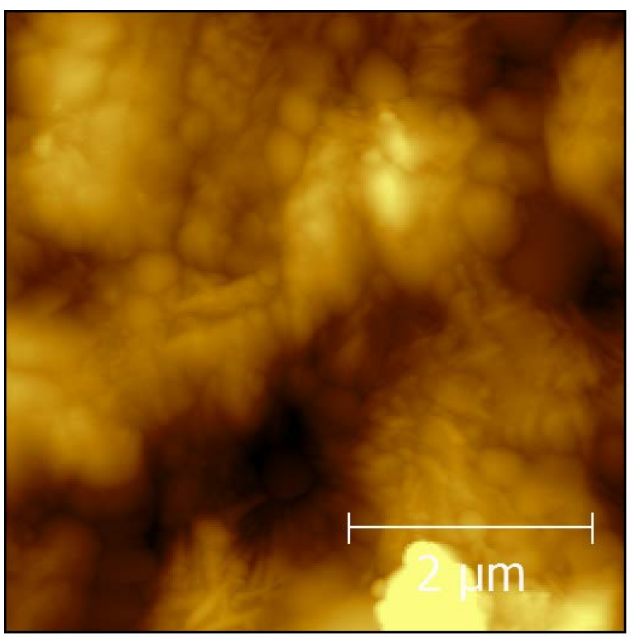

$\mathrm{e}$

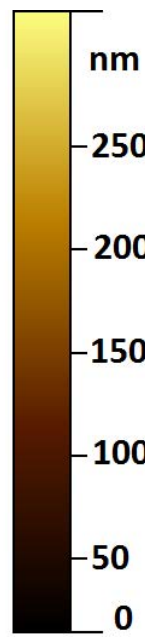

0
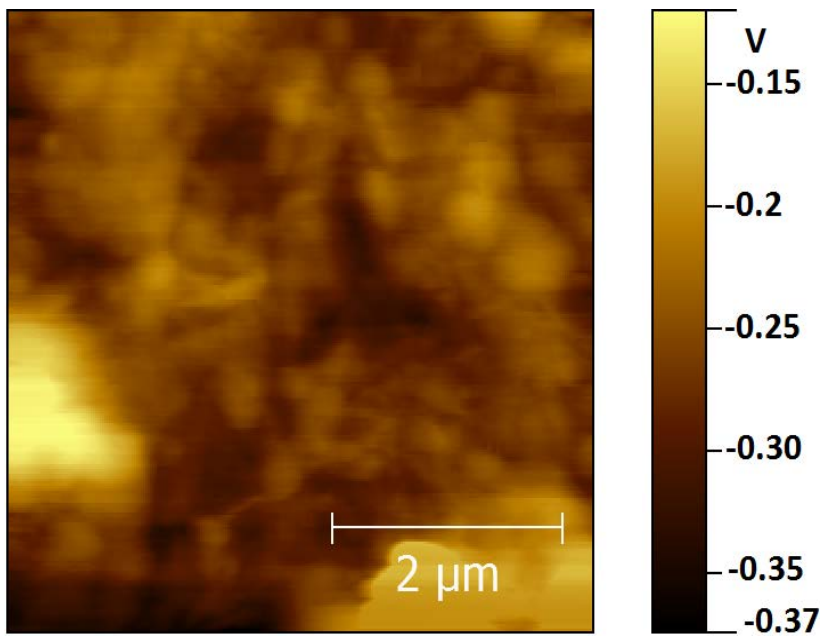

f

Fig. 3. AFM topography images for VDF-TeFE (a), HAP coating (c) and DCPA coating (e) and potential maps for VDF-TeFE (b), HAP coating (d) and DCPA coating (f).

It is known that a rough surface structure of $\mathrm{CaP}$ coatings stimulates the attachment of osteoblasts and differentiation of multipotent MSC into osteoblasts in in vitro systems and bone formation in in vivo systems [45-47]. Thus, it can be assumed that the rough surface of the coatings formed in this work will facilitate attachment of osteoblasts and bone formation in vivo.

Previously, we have shown that the surface of VDF-TeFE has a substantial negative potential $(>1.0 \mathrm{~V})$, due to the ferroelectric properties of the polymer [38]. The analysis of the surface potential maps presented in Fig. 4 (b, d, f) demonstrates that the coatings shift the surface potential in the positive direction and, therefore, it can be concluded that the formed coatings are positively charged.

The average surface potential for the CaP coatings was $-0.17 \pm 0.07 \mathrm{~V}$ and $-0.25 \pm$ $0.06 \mathrm{~V}$ for HAP and DCPA targets respectively (Fig. $3 \mathrm{~b}, \mathrm{~d}, \mathrm{f}$ ). The positive shift of the potential is possibly due to the fact that $\mathrm{CaP}$ nanostructured coating is a p-type semiconductor with a wide band gap ( $4 \mathrm{eV})$ and a high defect density [48]. The high defect density makes 
it possible to change the surface potential of the coatings with an external polarization or irradiation with low-energy electrons to further stimulate osteoblast adhesion to the surface $[49,50]$

The chemical composition of the surface is also an important characteristic of a biocompatible material. Since multipotent MSC express $\mathrm{Ca}^{2+}$-sensitive receptors that regulate their homing and differentiation potency, multipotent MSC differentiation into osteoblasts and new bone formation needs sufficient amount of calcium (Ca) and phosphorus (P) [51].

Table 1 presents the results of XRF studies of the chemical composition of the coatings. It shows that the coatings consist only of the elements of the sputtering target: Ca, $\mathrm{P}$, O (and Mg impurities). More than 40\% (for the HAP target coating) and more than $30 \%$ (for the DCPA target coating) are represented by $\mathrm{Ca}$ and $\mathrm{P}$.

Table 1. The elemental composition of the target and formed coatings

\begin{tabular}{|c|c|c|c|c|c|}
\hline \multirow{2}{*}{ Sample } & \multicolumn{4}{|c|}{ Element Composition, At. \% } & \multirow{2}{*}{$\mathrm{Ca} / \mathrm{P}$} \\
\hline & $\mathrm{Ca}$ & $\mathrm{P}$ & $\mathrm{Mg}$ & $\mathrm{O}$ & \\
\hline HAP & $26.6 \pm 0.1$ & $15.4 \pm 0.2$ & $0.7 \pm 0.2$ & $57.2 \pm 0.3$ & 1.72 \\
\hline Coating (HAP target) & $30.3 \pm 0.2$ & $16.2 \pm 0.1$ & $<0.2$ & $53.3 \pm 0.3$ & 1.87 \\
\hline DCPA & $17.9 \pm 0.1$ & $17.4 \pm 0.2$ & $0.2 \pm 0.1$ & $64.5 \pm 0.3$ & 1.04 \\
\hline Coating (DCPA target) & $19.1 \pm 0.1$ & $16.3 \pm 0.2$ & $<0.2$ & $64.4 \pm 0.5$ & 1.16 \\
\hline
\end{tabular}

A certain increase in the $\mathrm{Ca} / \mathrm{P}$ ratio for the coatings as compared with the sputtering targets was previously observed by other authors and can be due to a higher P volatility under low pressure [52,53] 
FTIR spectra of the initial polymer film, sputtering targets, the coatings and the reverse side of films after PLD are presented in Fig. 4. FTIR spectra of the film obtained from the solution of the copolymer VDF-TeFE has several major absorption bands characteristic of the ferroelectric $\beta$ phase: $881 \mathrm{~cm}^{-1}\left(v_{a} C F_{2}+r C H_{2}+r C F\right), 1325 \mathrm{~cm}^{-1}(w C H), 1398 \mathrm{~cm}^{-1}$ $\left(w \mathrm{CH}_{2}-v_{a} \mathrm{CC}\right)$ and $1429 \mathrm{~cm}^{-1}\left(\delta \mathrm{CH}_{2}\right)$ [54,55]. The spectrum also has $\alpha$-phase: characteristic band $617 \mathrm{~cm}^{-1}\left(\delta C F_{2}-\delta C C C\right)$ [56] and $\gamma$ phase: characteristic band $822^{-1} \mathrm{~cm}\left(r \mathrm{CH}_{2}\right)$ [57]. Thus, initial polymer film contains three phases, but the intensity and the presence of absorption bands in the region of $840 \mathrm{~cm}^{-1}\left(v_{s} C F_{2}\right)$ and $1276 \mathrm{~cm}^{-1}\left(v_{a s} C F_{2}\right)$, characteristic for molecular fragments with long trans sequences [58] allows us to conclude that a large proportion of the original polymer film is the $\beta$ phase with ferroelectric properties.

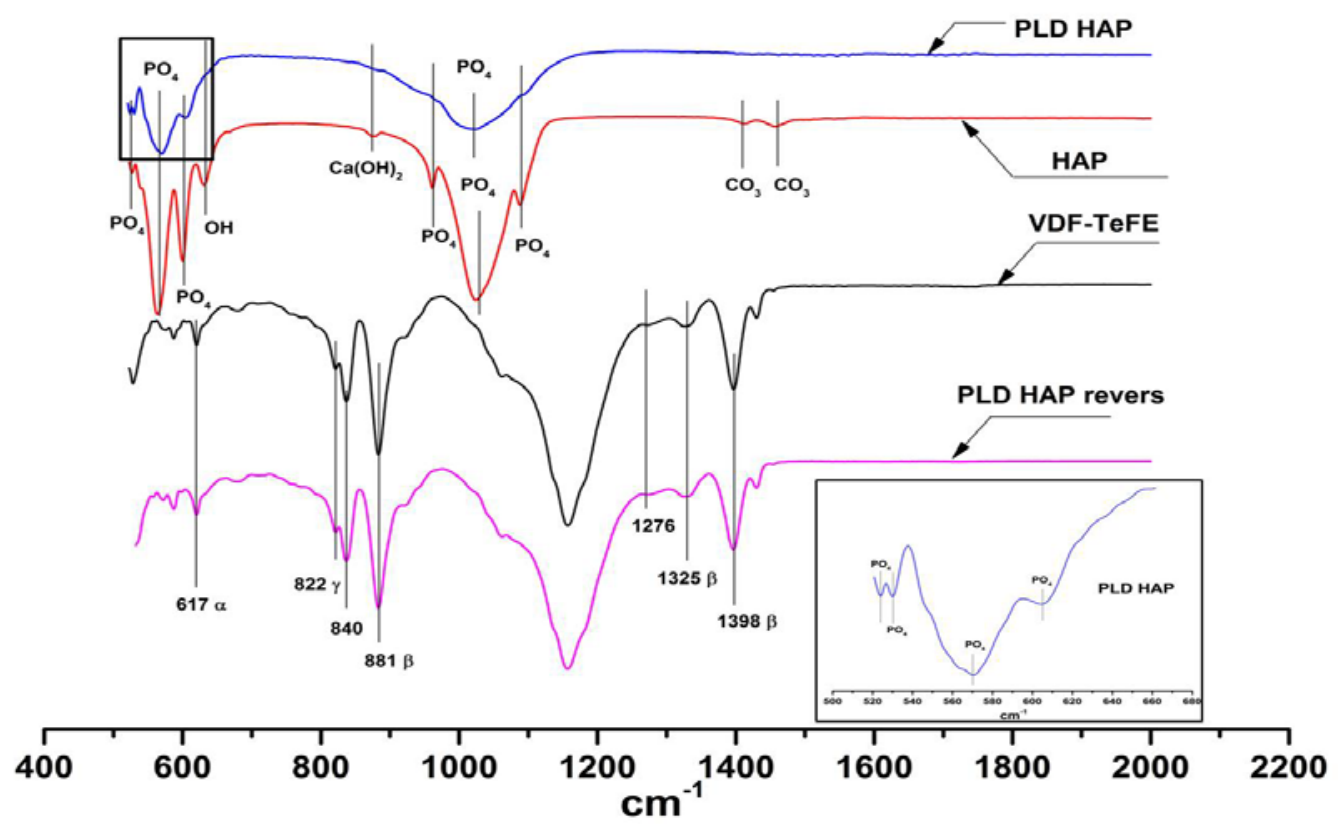




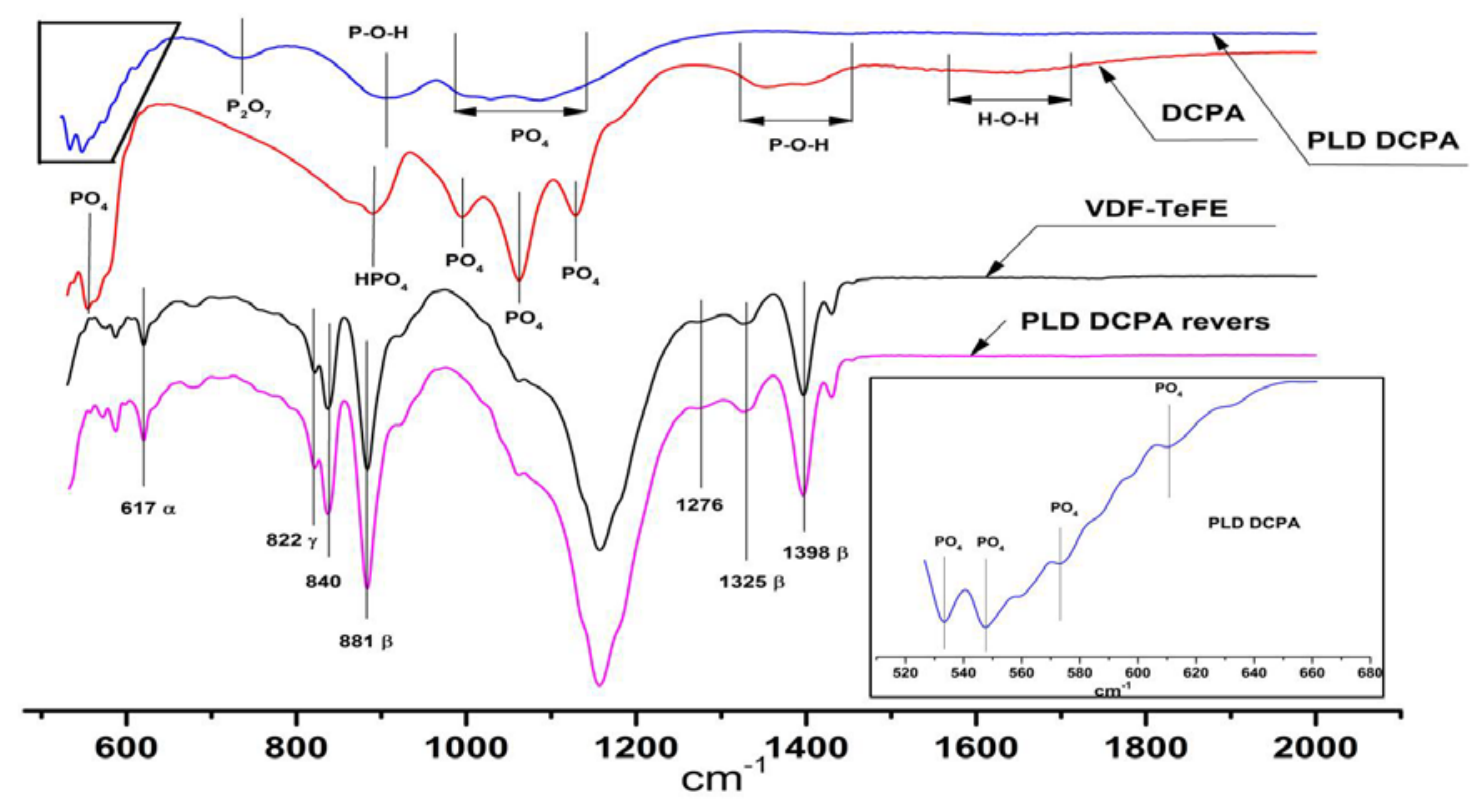

b

Fig. 4. FTIR spectra of the targets and the PLD coatings obtained with the HAP target (a) and DCPA target (b).

IR spectrum of the HAP powder has following major bands: $533 \mathrm{~cm}^{-1}, 563 \mathrm{~cm}^{-1}, 600$ $\mathrm{cm}^{-1}\left(v_{4} \mathrm{PO}^{3-}{ }_{4}\right), 963 \mathrm{~cm}^{-1}\left(v_{1} \mathrm{PO}^{3-}{ }_{4}\right), 1090 \mathrm{~cm}^{-1}\left(v_{3} \mathrm{PO}^{3-}{ }_{4}\right)$ and $1026 \mathrm{~cm}^{-1}\left(\mathrm{PO}^{3-}{ }_{4}\right)$ [59]. A weak band which may arise from the $\left(\mathrm{HPO}^{2-}{ }_{4}\right)$ at about $875 \mathrm{~cm}^{-1}$ appears on the FTIR spectrum. This band can also be connected with the presence of $\mathrm{Ca}(\mathrm{OH})_{2}$ in the sample. Following bands: $630 \mathrm{~cm}^{-1}$ (vibration mode $\left.\mathrm{OH}^{-}\right), 1412 \mathrm{~cm}^{-1}, 1456 \mathrm{~cm}^{-1}\left(v_{3} \mathrm{CO}_{3}\right)$ allow to characterize the HAP target as carbonate substituted hydroxyapatite [60].

IR spectrum of the DCPA powder has following major bands: $560 \mathrm{~cm}^{-1}\left(v_{4} \mathrm{PO}^{3-}{ }_{4}\right), 992$ $\mathrm{cm}^{-1}\left(v_{1} \mathrm{PO}^{3-}{ }_{4}\right)$ and $1060 \mathrm{~cm}^{-1}\left(v_{3} \mathrm{PO}^{3-}{ }_{4}\right)$. The band at $882 \mathrm{~cm}^{-1}$ corresponds to the $\mathrm{P}-\mathrm{O}(\mathrm{H})$ stretching vibrations of the acidic phosphate group $\left(\mathrm{HPO}_{4}\right)$. The broad peak at 1300 to 1450 $\mathrm{cm}^{-1}$ is due to the P-O-H in-plane bending, the broad band at approximately $1633 \mathrm{~cm}^{-1}$ is associated with the $\mathrm{H}-\mathrm{O}-\mathrm{H}$ bending and the rotation of the residual free water, $1125 \mathrm{~cm}^{-1}$ band was assigned to P-O stretching [61]. 
The IR spectrum of the PLD coating with the HAP target has following bands (Fig. 4 insert): $524 \mathrm{~cm}^{-1}, 530 \mathrm{~cm}^{-1}, 570 \mathrm{~cm}^{-1}, 605 \mathrm{~cm}^{-1}$ which are characteristic for the type $\left(v_{4} \mathrm{PO}^{3-}{ }_{4}\right)$ oscillations. The broad shoulder at $1000 \mathrm{~cm}^{-1}$ region is characteristic of $\left(v_{3} \mathrm{PO}^{3-}{ }_{4}\right)$ oscillations. There are small but quite distinct bands at $963 \mathrm{~cm}^{-1}\left(v_{1} \mathrm{PO}^{3-}{ }_{4}\right)$ and $1090 \mathrm{~cm}^{-1}\left(v_{3} \mathrm{PO}^{3-}{ }_{4}\right)$. Notable is the decrease, as compared to HAP powder, in the band intensity of $875 \mathrm{~cm}^{-1}$, as well as the absence of the band at $630 \mathrm{~cm}^{-1}$ which may be caused by the decomposition of $\mathrm{Ca}(\mathrm{OH})_{2}$ at a high temperature. Comparative analysis of the spectra of the HAP powder and the HAP target coating allows us to conclude that, under the parameters chosen to form a coating, there are no significant chemical changes in the structure during the transfer process of the target material to the substrate.

The IR spectrum of the PLD coating with the DCPA target has following bands which are characteristic for the type $\left(v_{4} \mathrm{PO}^{3-}{ }_{4}\right)$ oscillations: $533 \mathrm{~cm}^{-1}, 547 \mathrm{~cm}^{-1}, 573 \mathrm{~cm}^{-1}$ и $610 \mathrm{~cm}^{-1}$. The band at $887 \mathrm{~cm}^{-1}$ corresponds to the $\mathrm{P}-\mathrm{O}-\mathrm{H}$ stretching vibrations of the acidic phosphate group $\left(\mathrm{HPO}_{4}\right)$ and is an evidence of the formation of calcium-deficient apatite . The broad shoulder at $732 \mathrm{~cm}^{-1}$ is characteristic of the group $\mathrm{P}_{2} \mathrm{O}_{7}$ [62].

The presence in the coating formed from the target DCPA bands at $732 \mathrm{~cm}^{-1}$ and 887 $\mathrm{cm}^{-1}$ and the absence of the band at $1060 \mathrm{~cm}^{-1}$ suggest a significant change in the chemical structure of the target material in the process of transfer onto the substrate. Changes in the chemical structure of the target material are due to the thermal decomposition of DCPA at high temperature. It is known that upon heating DCPA is transformed into calcium pyrophosphate (CPP, $\mathrm{Ca}_{2} \mathrm{P}_{2} \mathrm{O}_{7}$ ) by reactions described in [63]:

$$
\begin{aligned}
& 2 \mathrm{CaHPO}_{4} \rightarrow(\delta) \mathrm{Ca}_{2} \mathrm{P}_{2} \mathrm{O}_{7}+\mathrm{H}_{2} \mathrm{O} \\
& (\delta) \mathrm{Ca}_{2} \mathrm{P}_{2} \mathrm{O}_{7} \rightarrow(\beta) \mathrm{Ca}_{2} \mathrm{P}_{2} \mathrm{O}_{7}
\end{aligned}
$$


Therefore, the results are indicative of the DCPA target coating being enriched with CPP. Previously it was assumed that the presence of calcium phosphate CPP in materials intended for bone regeneration could negatively affect the process of bone regeneration. However, recent studies show that bone cements enriched in CPP, had not inhibited mineralization of the healing bone around the implant and actually appeared to stimulate it [64]. Thus, the presence of CPP in the coatings obtained by sputtering the DCPA target may be a factor in stimulating new bone formation process in vivo, however, this assumption requires further detailed study.

The FTIR spectrum of the back side of the polymer film after the coating has bands characteristic of all polymorphs: $\beta\left(881 \mathrm{~cm}^{-1}, 1325 \mathrm{~cm}^{-1}, 1398 \mathrm{~cm}^{-1}\right.$ and $\left.1429 \mathrm{~cm}^{-1}\right), \gamma\left(822 \mathrm{~cm}^{-}\right.$ $\left.{ }^{1}\right)$ and $\alpha\left(617 \mathrm{~cm}^{-1}\right)$. The absence of the absorption band shifts, as well as the presence of characteristic absorption bands for trans-long sequences $\left(840 \mathrm{~cm}^{-1}, 1276 \mathrm{~cm}^{-1}\right)$ indicates the preservation of the original crystalline structure of the film during the formation of the coating.

XRD patterns of the original target and the resulting coatings are shown in Fig. 5.

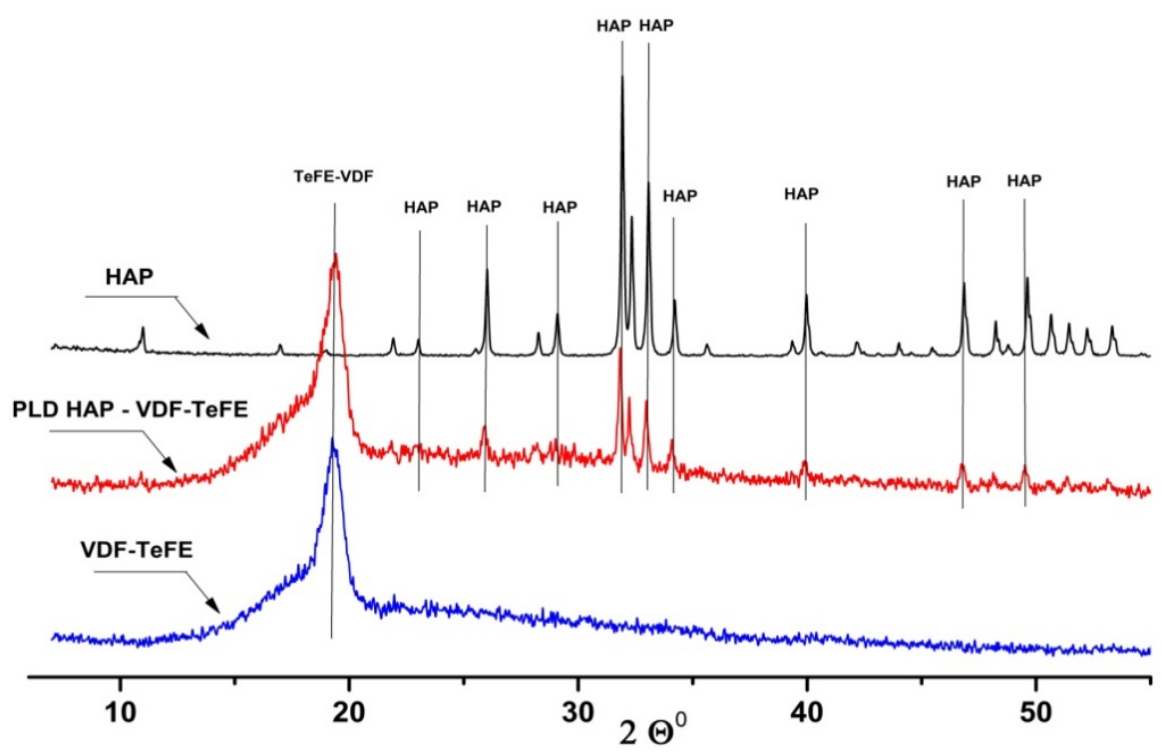




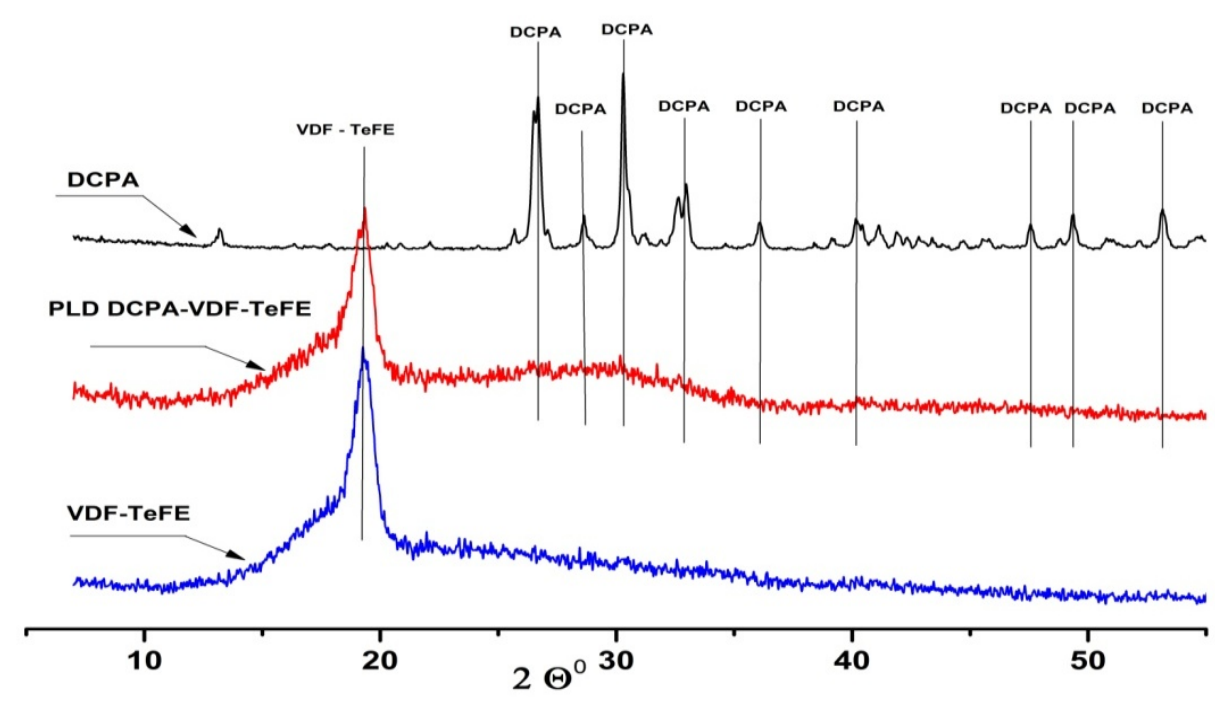

b

Fig.5. XRD patterns of the samples: a) the original polymer film, the film with the coating formed using HAP target and HAP; b) the original polymer film, the film with the coating formed using DCPA target and DCPA.

On the patterns of the original VDF-TeFE film, there is a high peak at $19.6^{\circ}$, which corresponds to the orthorhombic lattice with polar cells, in which the chains have transconformation characteristic of the $\beta$ phase [65]. The peak-halo at angles near $2 \theta=18^{\circ}$ were recognized as a paraelectric $\alpha$ phase and ferroelectric $\gamma$ phase localized in the interfacial domains at the crystal-amorphous phase boundaries [66,67]. Thus, the XRD investigation of the structure of the coatings indicates the presence of crystalline phases with the ferroelectric properties of the film.

On the XRD patterns of the HAP target (Fig 5a) there are a number of intensive peaks: $26.0^{\circ}(002), 31.9^{\circ}(211), 32.3^{\circ}(112), 33.1^{\circ}(300), 34.2^{\circ}(202), 39.9^{\circ}(310), 46.8^{\circ}(222)$ and $49.6^{\circ}(213)$ as well as weak peaks: $21.8^{\circ}(200), 23.0^{\circ}(111), 28.2^{\circ}(210), 35.6^{\circ}(301), 39.3^{\circ}$ (212), $42.1^{\circ}(311), 43.9^{\circ}(113), 45.6^{\circ}$ (203), 50.7 $(321), 51.4^{\circ}(410)$ and $52.2^{\circ}$ (402) which correspond to the structure of hydroxyapatite $\left(\mathrm{Ca}_{10}\left(\mathrm{PO}_{4}\right)_{6}(\mathrm{OH})_{2}\right)$. 
On the XRD patterns of the DCPA target (Fig 5b) a series of intensive peaks was observed at: $26.7^{\circ}(002), 28.6^{\circ}(112), 30.3^{\circ}(120), 32.9^{\circ}(121), 36.1^{\circ}(112)$ and $49.4^{\circ}(321)$ which is consistent with the monetite structure.

On the XRD patterns of the polymer films with the HAP target coating there are peaks corresponding to the original target material: $26.0^{\circ}(002), 31.9^{\circ}(211), 32.3^{\circ}(112), 33.1^{\circ}$ (300), $34.2^{\circ}(202), 39.9^{\circ}(310), 46.8^{\circ}(222), 49.6^{\circ}$ (213) and peak at $19.6^{\circ}$, corresponding to VDF-TeFE film substrate.

The XRD study results support the assumption that under the selected parameters the transfer of target particles to the substrate occurs without significant changes in the structure of HAP, which is associated with a significant thermal stability of HAP. It is known that changes in the crystal structure of HAP during heating in an oxidizing atmosphere, as recorded by $\mathrm{XRD}$, begins at a temperature above $1300^{\circ} \mathrm{C}$ [68]. The presence of crystalline phases detected in the HAP target coating suggests the formation of $\mathrm{CaP}$ coating from the liquid phase by rapid cooling and fusion melt of HAP drops. This conclusion is based on an assumption that the coating formed from highly ionized plasma would be amorphous, whereas in the case of the coating formation from liquid drops of HAP with a nucleus consisting of unmelted target, crystalline phases are expected in the coating.

On the XRD patterns the polymer films with the DCPA target coating, in addition to the peak at $19.6^{\circ}$ corresponding to the film substrate, there is a broad structureless band (halo) in the field of intensive peaks of original DCPA target $\left(26.7^{\circ}, 28.6^{\circ}, 30.3^{\circ}\right.$ and $\left.32.9^{\circ}\right)$ indicating the amorphous structure of the coating. Thus, the results obtained by XRD confirm the assumption that during the transfer of the target material to a substrate there is a change in the chemical structure of the coating by thermal decomposition of DCPA. 
It should be noted that the presence of constant peak at $19.6^{\circ}$ for both types of coatings suggests that the crystal structure of the copolymer VDF-TeFE does not change during formation of CaP coatings by PLD, confirming the results obtained by FTIR study. Hence, our studies demonstrate that crystalline or amorphous CaP coatings on VDF-TeFE are possible, with HAP or DCPA target material respectively, without the change of the crystal structure of the polymeric substrate material.

The results of studies on the influence of the coatings on the viability of the MSC culture cultivated for 72 hours are shown in Table 2. The images of fluorescently labeled cells on the surface of the formed coatings are given in Fig. 6.

Table 2. The results of MSC viability studies.

\begin{tabular}{cccc}
\hline \multirow{2}{*}{ Coating type } & \multicolumn{3}{c}{ Relative amount of MSC, (Me (25\%; 75\%)) } \\
\cline { 2 - 4 } & Viable, \% & Apoptosis, \% & Necrosis, \% \\
\hline $\begin{array}{c}\text { Coating (VDF- } \\
\text { TeFE) }\end{array}$ & $89.6(88.5 ; 90.1)$ & $6.1(4.4 ; 6.5)$ & $3.3(2.4 ; 4.2)$ \\
\hline $\begin{array}{c}\text { Coating (HAP } \\
\text { target) }\end{array}$ & $90.5(90.5 ; 93.0)$ & $4.9(3.4 ; 5.3)$ & $3.0(1.2 ; 3.3)$ \\
\hline $\begin{array}{c}\text { Coating (DCPA } \\
\text { target) }\end{array}$ & $87.6(85.5 ; 90.8)$ & $7.9(5.2 ; 9.4)$ & $2.7(2.2 ; 3.7)$ \\
\hline Control & $87.4(84.9 ; 90.6)$ & $4.5(4.3 ; 4.8)$ & $7.1(3.3 ; 9.1)$ \\
\hline
\end{tabular}

Importantly, for the surface of samples with the VDF-TeFE coating there were almost no cell adhesion (Fig. 6 a, b). While the density of cells on samples with the HAP target coating and the DCPA target coating amounted to $615 \pm 122$ (Fig. 6 c, d) and $532 \pm 185$ (Fig. $6 \mathrm{e}, \mathrm{f}$ ) on $1 \mathrm{~mm}^{2}$ of the surface respectively.

The low number of cells observed on the surface of the film of the copolymer VDFTeFE is explained by the contact surface properties. It is known that coatings formed from solution of the copolymer VDF-TeFE are characterized by a low roughness, a high hydrophobicity, and thus have a low surface free energy value [38]. It has been reported that 20 
the hydrophobic surface is capable of absorbing a large number of proteins [69] which typically inhibits cell adhesion [70].

A significant number of cells observed on the surface of the CaP coatings formed by the PLD method with HAP target are due to the rough surface topography and high content of $\mathrm{Ca}$ and $\mathrm{P}$ in the formed coatings. This ability of the coatings to create conditions for attachment and proliferation of osteoblasts on the surface was previously shown in [34], [71]

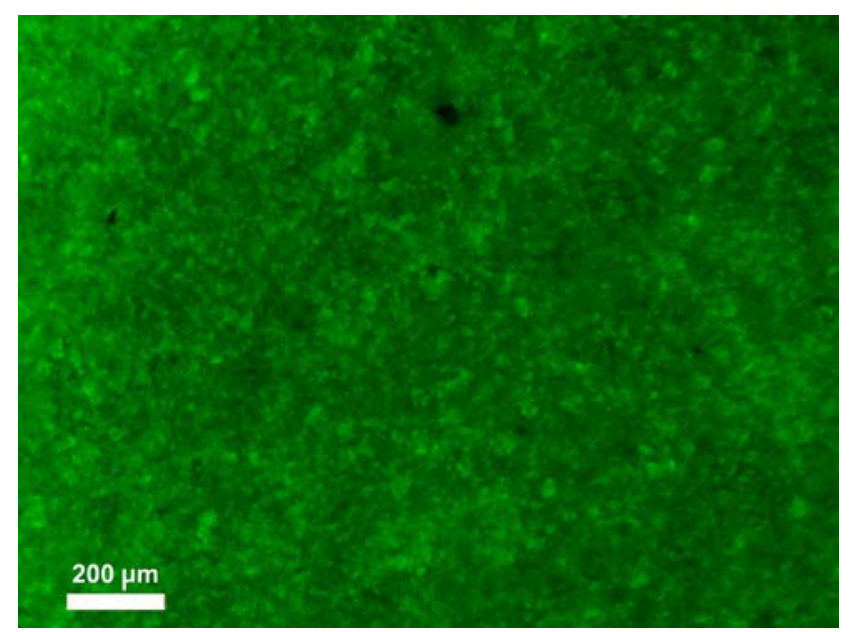

a

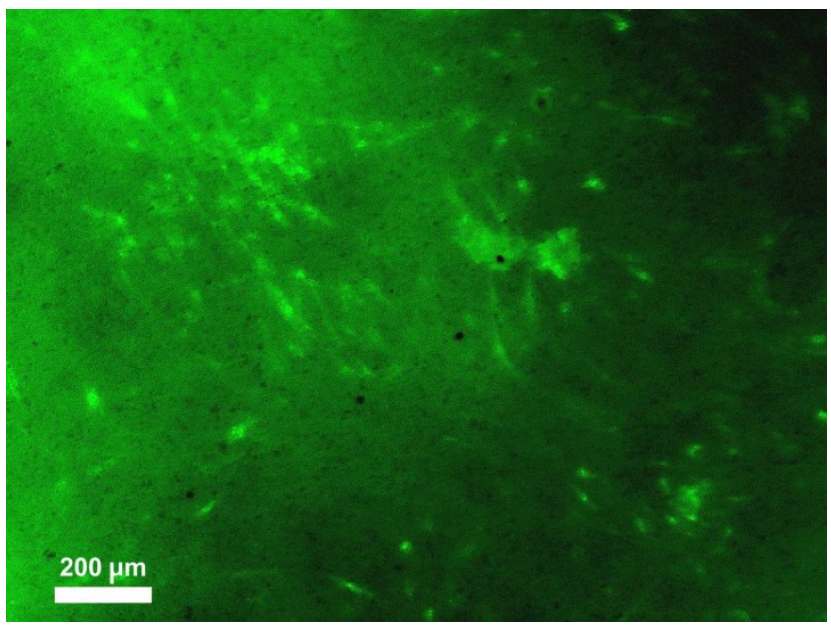

C

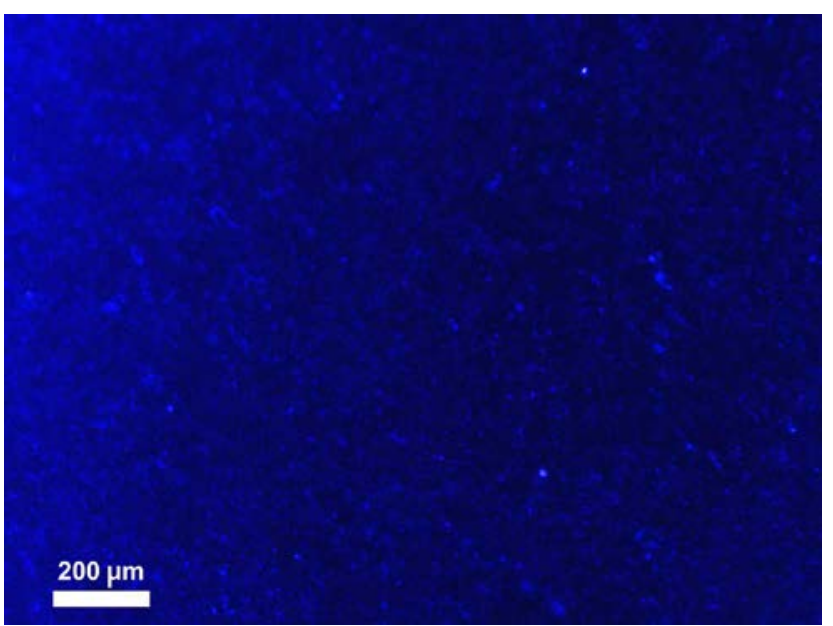

b

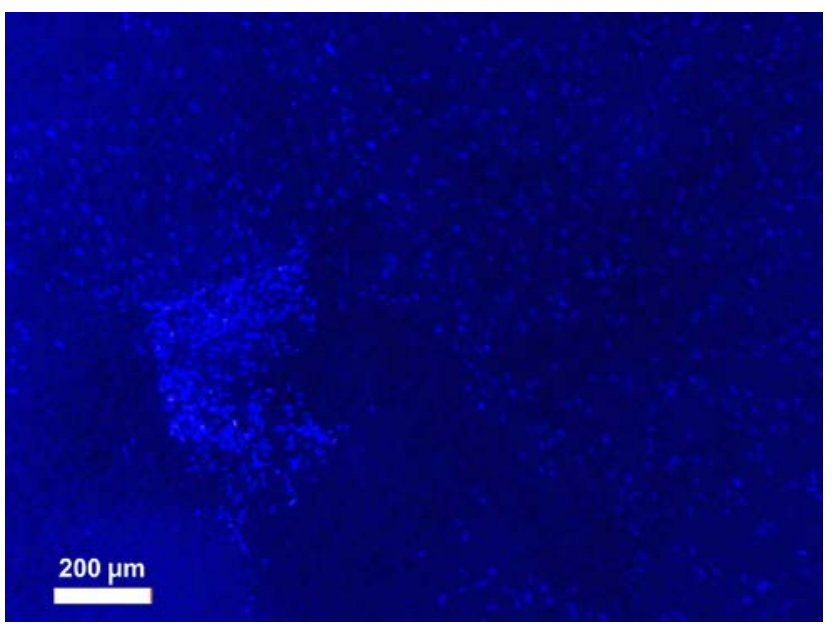

d 


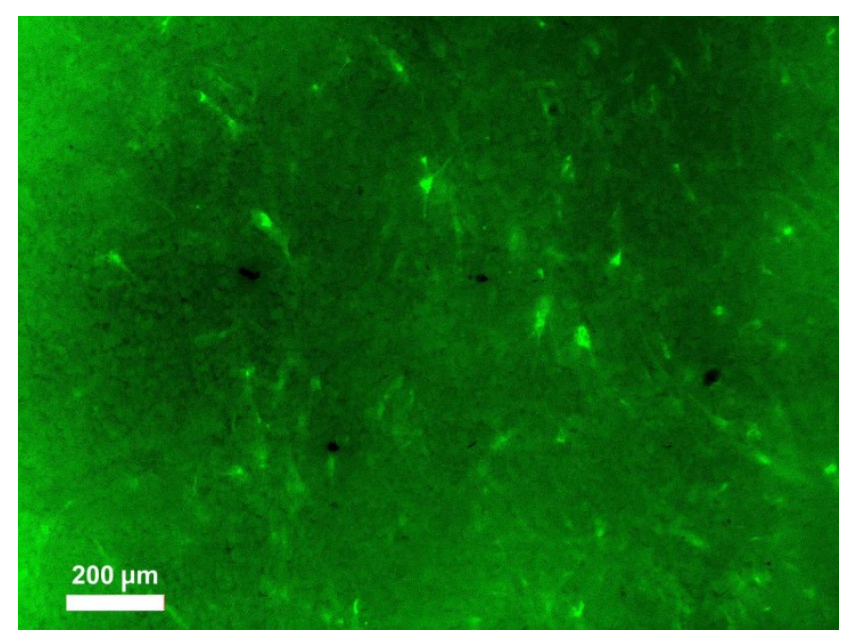

e

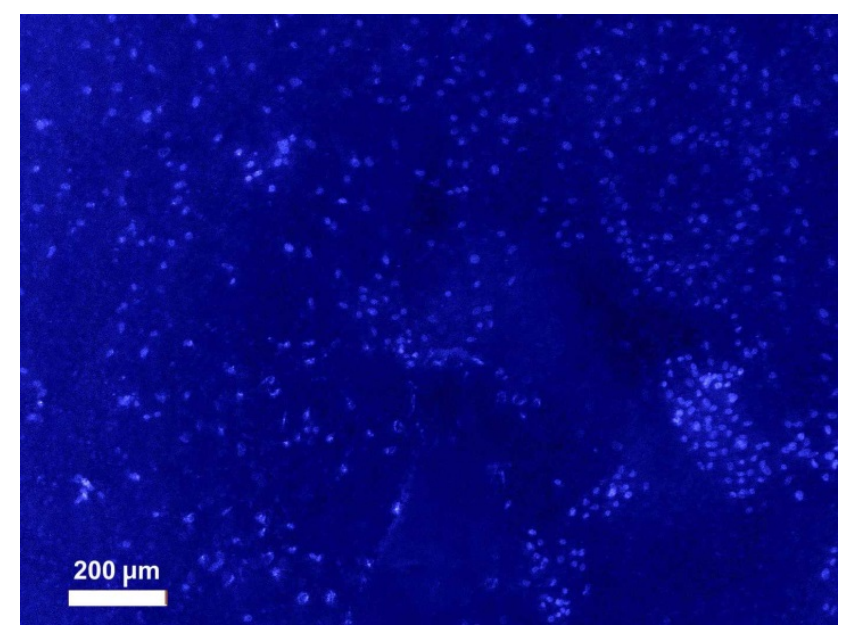

f

Fig. 6. Images of cells at the surface of coatings VDF-TeFE (a - GFP, b - DAPI), HAP coating (cGFP, $d-D A P I)$ and DCPA coating (e - GFP, $f-D A P I)$

The absence of significant differences in terms of adhesion and cell viability on the surface of the CaP coatings formed using the DCPA and the HAP targets demonstrates the lack of toxicity of the DCPA based coatings. Thus, the presented studies show the possibility of using PLD with the DCPA target for forming biocompatible coatings.

\section{Conclusions.}

This paper presents the results of studies of the properties of calcium phosphate coatings formed on the surface of the copolymer VDF-TeFE by laser ablation with HPA and DCPA targets. Studies of the coatings by SEM and AFM demonstrated that regardless of the type of sputtering target the structure of $\mathrm{CaP}$ coatings was rough which is potentially conducive to the attachment and proliferation of osteoblasts. The structure of the coatings suggests that, under the selected formation parameters, the formation of the coating is predominantly from a liquid phase.

The chemical composition of the coatings is similar to the sputtering target. Some observed deviation of the ratio $\mathrm{Ca} / \mathrm{P}$ in the coatings compared with the sputtering targets is 
due to the higher volatility of the phosphorus at low pressure and high temperature. In the case of the HAP target there is no significant change in the structure of the target material during the formation of the coating, which is due to significant thermal stability of HAP. In the case of the DCPA target the coating consists of amorphous CaP enriched with CPP.

The studies of the crystal structure of the ferroelectric polymer material before and after the formation of the coatings by PLD indicate that the formation of CaP coatings do not affect the crystalline structure of the polymer material, which indicates the conservation of the properties of the ferroelectric film. The toxicity studies of the coatings show that the obtained coatings are non-toxic.

\section{Acknowledgments}

This work was financially supported by the Federal Target Program (agreement \#14.578.21.0031, unique identifier RFMEFI57714X0036); Russian Foundation for Basic Research (projects \#13-08-98052 r_sibir_a), and the Russian Ministry of Education and Science (State Assignment \#2014/223, Project code \#1347). The authors are grateful for the contributions of in the research of the Tomsk regional common use center (agreement \#14.594.21.0001).

\section{References}

[1] B. Seal, Polymeric biomaterials for tissue and organ regeneration, Mater. Sci. Eng. R Reports. 34 (2001) 147-230. doi:10.1016/S0927-796X(01)00035-3.

[2] E.J. Kim, J.P. Berg, M.P. Weikert, L. Kong, M.B. Hamill, D.D. Koch, et al., Scleralfixated capsular tension rings and segments for ectopia lentis in children., Am. J. Ophthalmol. 158 (2014) 899-904.e1. doi:10.1016/j.ajo.2014.08.002.

[3] F. Rüfer, J. Eisenack, A. Klettner, R. Zeuner, J. Hillenkamp, G. Westphal, et al., Multilayered Gore-Tex patch for temporary coverage of deep noninfectious corneal defects: surgical procedure and clinical experience., Am. J. Ophthalmol. 151 (2011) 703-713.e2. doi:10.1016/j.ajo.2010.10.025. 
[4] M. Bosiers, K. Deloose, J. Verbist, H. Schroë, G. Lauwers, W. Lansink, et al., Heparinbonded expanded polytetrafluoroethylene vascular graft for femoropopliteal and femorocrural bypass grafting: 1-year results., J. Vasc. Surg. 43 (2006) 313-8; discussion 318-9. doi:10.1016/j.jvs.2005.10.037.

[5] K. Junge, R. Rosch, U. Klinge, C. Krones, B. Klosterhalfen, P.R. Mertens, et al., Gentamicin supplementation of polyvinylidenfluoride mesh materials for infection prophylaxis., Biomaterials. 26 (2005) 787-93. doi:10.1016/j.biomaterials.2004.02.070.

[6] J.S. de C. Campos, A.A. Ribeiro, C.X. Cardoso, Preparation and characterization of PVDF/CaCO3 composites, Mater. Sci. Eng. B. 136 (2007) 123-128. doi:10.1016/j.mseb.2006.09.017.

[7] A.M. Aronov, E.N. Bol’basov, V. V. Guzeev, M. V. Dvornichenko, S.I. Tverdokhlebov, I.A. Khlusov, Biological Composites Based on Fluoropolymers with Hydroxyapatite for Intramedullary Implants, Biomed. Eng. (NY). 44 (2010) 108-113. doi:10.1007/s10527-010-9166-9.

[8] V.A. Schulte, Y. Hu, M. Diez, D. Bünger, M. Möller, M.C. Lensen, A hydrophobic perfluoropolyether elastomer as a patternable biomaterial for cell culture and tissue engineering., Biomaterials. 31 (2010) 8583-95. doi:10.1016/j.biomaterials.2010.07.070.

[9] Y.-S. Lee, G. Collins, T.L. Arinzeh, Neurite extension of primary neurons on electrospun piezoelectric scaffolds., Acta Biomater. 7 (2011) 3877-86. doi:10.1016/j.actbio.2011.07.013.

[10] Z. Cui, E. Drioli, Y.M. Lee, Recent progress in fluoropolymers for membranes, Prog. Polym. Sci. 39 (2014) 164-198. doi:10.1016/j.progpolymsci.2013.07.008.

[11] R. Souzy, B. Ameduri, Functional fluoropolymers for fuel cell membranes, Prog. Polym. Sci. 30 (2005) 644-687. doi:10.1016/j.progpolymsci.2005.03.004.

[12] V. V Kochervinskii, The structure and properties of block poly(vinylidene fluoride) and systems based on it, Russ. Chem. Rev. 65 (2007) 865-913. doi:10.1070/RC1996v065n10ABEH000328.

[13] T. Furukawa, Ferroelectric properties of vinylidene fluoride copolymers, Phase Transitions. 18 (1989) 143-211. doi:10.1080/01411598908206863.

[14] P. Martins, A.C. Lopes, S. Lanceros-Mendez, Electroactive phases of poly(vinylidene fluoride): Determination, processing and applications, Prog. Polym. Sci. 39 (2014) 683-706. doi:10.1016/j.progpolymsci.2013.07.006.

[15] S.M. Damaraju, S. Wu, M. Jaffe, T.L. Arinzeh, Structural changes in PVDF fibers due to electrospinning and its effect on biological function., Biomed. Mater. 8 (2013) 045007. doi:10.1088/1748-6041/8/4/045007. 
[16] C. Ribeiro, J. Pärssinen, V. Sencadas, V. Correia, S. Miettinen, V.P. Hytönen, et al., Dynamic piezoelectric stimulation enhances osteogenic differentiation of human adipose stem cells., J. Biomed. Mater. Res. A. (2014). doi:10.1002/jbm.a.35368.

[17] J.J. Ficat, G. Escourrou, M.J. Fauran, R. Durroux, P. Ficat, C. Lacabanne, et al., Osteogenesis induced by bimorph polyvinylidene fluoride films, Ferroelectrics. 51 (2011) 121-128. doi:10.1080/00150198308009062.

[18] A.A. Marino, J. Rosson, E. Gonzalez, L. Jones, S. Rogers, E. Fukada, Quasi-static charge interactions in bone, J. Electrostat. 21 (1988) 347-360. doi:10.1016/03043886(88)90036-8.

[19] Y.S. Lee, G. Collins, T. Livingston Arinzeh, Neurite extension of primary neurons on electrospun piezoelectric scaffolds, Acta Biomater. 7 (2011) 3877-3886. doi:10.1016/j.actbio.2011.07.013.

[20] Y.-S. Lee, T.L. Arinzeh, The influence of piezoelectric scaffolds on neural differentiation of human neural stem/progenitor cells., Tissue Eng. Part A. 18 (2012) 2063-72. doi:10.1089/ten.TEA.2011.0540.

[21] C. Frias, J. Reis, F. Capela e Silva, J. Potes, J. Simões, A.T. Marques, Polymeric piezoelectric actuator substrate for osteoblast mechanical stimulation., J. Biomech. 43 (2010) 1061-6. doi:10.1016/j.jbiomech.2009.12.010.

[22] C. Frias, J. Reis, F. Capela e Silva, J. Potes, J. Simões, A.T. Marques, Piezoelectric actuator: Searching inspiration in nature for osteoblast stimulation, Compos. Sci. Technol. 70 (2010) 1920-1925. doi:10.1016/j.compscitech.2010.06.011.

[23] G. Jin, Q. Yao, S. Zhang, L. Zhang, Surface modifying of microporous PTFE capillary for bilirubin removing from human plasma and its blood compatibility, Mater. Sci. Eng. C. 28 (2008) 1480-1488. doi:10.1016/j.msec.2008.04.008.

[24] T.-H. Young, H.-H. Chang, D.-J. Lin, L.-P. Cheng, Surface modification of microporous PVDF membranes for neuron culture, J. Memb. Sci. 350 (2010) 32-41. doi:10.1016/j.memsci.2009.12.009.

[25] D. Klee, Z. Ademovic, A. Bosserhoff, H. Hoecker, G. Maziolis, H.-J. Erli, Surface modification of poly(vinylidenefluoride) to improve the osteoblast adhesion, Biomaterials. 24 (2003) 3663-3670. doi:10.1016/S0142-9612(03)00235-7.

[26] B. Feddes, J.G.. Wolke, A.. Vredenberg, J.. Jansen, Adhesion of calcium phosphate ceramic on polyethylene (PE) and polytetrafluoroethylene (PTFE), Surf. Coatings Technol. 184 (2004) 247-254. doi:10.1016/j.surfcoat.2003.10.013.

[27] D.V. Shtansky, A.S. Grigoryan, A.K. Toporkova, A.V. Arkhipov, A.N. Sheveyko, P.V. Kiryukhantsev-Korneev, Modification of polytetrafluoroethylene implants by depositing TiCaPCON films with and without stem cells, Surf. Coatings Technol. 206 (2011) 1188-1195. doi:10.1016/j.surfcoat.2011.08.029. 
[28] P. Habibovic, H. Yuan, C.M. van der Valk, G. Meijer, C.A. van Blitterswijk, K. de Groot, 3D microenvironment as essential element for osteoinduction by biomaterials., Biomaterials. 26 (2005) 3565-75. doi:10.1016/j.biomaterials.2004.09.056.

[29] D. V. Shtansky, I. V. Batenina, P. V. Kiryukhantsev-Korneev, A.N. Sheveyko, K.A. Kuptsov, I.Y. Zhitnyak, et al., Ag- and Cu-doped multifunctional bioactive nanostructured TiCaPCON films, Appl. Surf. Sci. 285 (2013) 331-343. doi:10.1016/j.apsusc.2013.07.169.

[30] V.F. Pichugin, R.A. Surmenev, E. V. Shesterikov, M.A. Ryabtseva, E. V. Eshenko, S.I. Tverdokhlebov, et al., The preparation of calcium phosphate coatings on titanium and nickel-titanium by rf-magnetron-sputtered deposition: Composition, structure and micromechanical properties, Surf. Coatings Technol. 202 (2008) 3913-3920. doi:10.1016/j.surfcoat.2008.01.038.

[31] S.I. Tverdokhlebov, E.N. Bolbasov, E.V. Shesterikov, L.V. Antonova, A.S. Golovkin, V.G. Matveeva, et al., Modification of polylactic acid surface using RF plasma discharge with sputter deposition of a hydroxyapatite target for increased biocompatibility, Appl. Surf. Sci. 329 (2015) 32-39. doi:10.1016/j.apsusc.2014.12.127.

[32] P. Baeri, L. Torrisi, N. Marino, G. Foti, Ablation of hydroxyapatite by pulsed laser irradiation, Appl. Surf. Sci. 54 (1992) 210-214. doi:10.1016/0169-4332(92)90046-Z.

[33] Y.S. Tveryanovich, A.A. Manshina, A.S. Tverjanovich, Production of nanodispersed materials and thin films by laser ablation techniques in liquid and in vacuum, Russ. Chem. Rev. 81 (2012) 1091-1116. doi:10.1070/RC2012v081n12ABEH004285.

[34] L. Duta, F.N. Oktar, G.E. Stan, G. Popescu-Pelin, N. Serban, C. Luculescu, et al., Novel doped hydroxyapatite thin films obtained by pulsed laser deposition, Appl. Surf. Sci. 265 (2013) 41-49. doi:10.1016/j.apsusc.2012.10.077.

[35] A. Kurella, N.B. Dahotre, Review paper: surface modification for bioimplants: the role of laser surface engineering., J. Biomater. Appl. 20 (2005) 5-50. doi:10.1177/0885328205052974.

[36] S. Shadanbaz, J. Walker, T.B.F. Woodfield, M.P. Staiger, G.J. Dias, Monetite and brushite coated magnesium: in vivo and in vitro models for degradation analysis., J. Mater. Sci. Mater. Med. 25 (2014) 173-83. doi:10.1007/s10856-013-5059-2.

[37] F. Tamimi, J. Torres, U. Gbureck, E. Lopez-Cabarcos, D.C. Bassett, M.H. Alkhraisat, et al., Craniofacial vertical bone augmentation: a comparison between 3D printed monolithic monetite blocks and autologous onlay grafts in the rabbit., Biomaterials. 30 (2009) 6318-26. doi:10.1016/j.biomaterials.2009.07.049.

[38] S.I. Tverdokhlebov, E.N. Bolbasov, E.V. Shesterikov, A.I. Malchikhina, V.A. Novikov, Y.G. Anissimov, Research of the surface properties of the thermoplastic copolymer of vinilidene fluoride and tetrafluoroethylene modified with radio-frequency magnetron sputtering for medical application, Appl. Surf. Sci. 263 (2012) 187-194. doi:10.1016/j.apsusc.2012.09.025. 
[39] V.A. Klimenov, S.I. Tverdokhlebov, E.N. Bol’basov, E. V. Shesterikov, V.A. Novikov, T.L. Volokitina, Application of atomic force microscopy methods for testing the surface parameters of coatings of medical implants, Russ. J. Nondestruct. Test. 47 (2012) 771-782. doi:10.1134/S1061830911110040.

[40] R.I. Dmitrieva, I.R. Minullina, A.A. Bilibina, O. V. Tarasova, S. V. Anisimov, A.Y. Zaritskey, Bone marrow- and subcutaneous adipose tissue-derived mesenchymal stem cells: Differences and similarities, Cell Cycle. 11 (2012) 377-383. doi:10.4161/cc.11.2.18858.

[41] A. Malashicheva, B. Kanzler, E. Tolkunova, D. Trono, A. Tomilin, Lentivirus as a tool for lineage-specific gene manipulations, Genesis. 45 (2007) 456-459. doi:10.1002/dvg.20313.

[42] W. Mróz, A. Bombalska, B. Budner, S. Burdyńska, M. Jedyński, A. Prokopiuk, et al., Comparative study of hydroxyapatite and octacalcium phosphate coatings deposited on metallic implants by PLD method, Appl. Phys. A Mater. Sci. Process. 101 (2010) 713716. doi:10.1007/s00339-010-5926-3.

[43] J.L. Arias, M.B. Mayor, J. Pou, Y. Leng, B. León, M. Pérez-Amor, Micro- and nanotesting of calcium phosphate coatings produced by pulsed laser deposition, Biomaterials. 24 (2003) 3403-3408. doi:10.1016/S0142-9612(03)00202-3.

[44] Q. Bao, C. Chen, D. Wang, Q. Ji, T. Lei, Pulsed laser deposition and its current research status in preparing hydroxyapatite thin films, Appl. Surf. Sci. 252 (2005) 1538-1544. doi:10.1016/j.apsusc.2005.02.127.

[45] I.N. Mihailescu, P. Torricelli, A. Bigi, I. Mayer, M. Iliescu, J. Werckmann, et al., Calcium phosphate thin films synthesized by pulsed laser deposition: Physico-chemical characterization and in vitro cell response, Appl. Surf. Sci. 248 (2005) 344-348. doi:10.1016/j.apsusc.2005.03.111.

[46] D. Popkov, P. Lascombes, A. Popkov, P. Journeau, T. Haumont, Role of the flexible intramedullary nailing in limb lengthening in children: Comparative study based on the series of 294 lengthenings, Eur. Orthop. Traumatol. 3 (2012) 17-24. doi:10.1007/s12570-012-0090-1.

[47] A. V. Popkov, N.A. Kononovich, E.N. Gorbach, S.I. Tverdokhlebov, Y.M. Irianov, D.A. Popkov, Bone Healing by Using Ilizarov External Fixation Combined with Flexible Intramedullary Nailing versus Ilizarov External Fixation Alone in the Repair of Tibial Shaft Fractures: Experimental Study, Sci. World J. 2014 (2014) 1-8. doi:10.1155/2014/239791.

[48] D. Aronov, G. Rosenman, Trap state spectroscopy studies and wettability modification of hydroxyapatite nanobioceramics, J. Appl. Phys. 101 (2007) 034701. doi:10.1063/1.2433702.

[49] S. Bodhak, S. Bose, A. Bandyopadhyay, Electrically polarized HAp-coated Ti: in vitro bone cell-material interactions., Acta Biomater. 6 (2010) 641-51. doi:10.1016/j.actbio.2009.08.008. 
[50] D. Aronov, R. Rosen, E.Z. Ron, G. Rosenman, Electron-induced surface modification of hydroxyapatite-coated implant, Surf. Coatings Technol. 202 (2008) 2093-2102. doi:10.1016/j.surfcoat.2007.08.060.

[51] G.B. Adams, K.T. Chabner, I.R. Alley, D.P. Olson, Z.M. Szczepiorkowski, M.C. Poznansky, et al., Stem cell engraftment at the endosteal niche is specified by the calcium-sensing receptor., Nature. 439 (2006) 599-603. doi:10.1038/nature04247.

[52] M. Katto, K. Kurosawa, A. Yokotani, S. Kubodera, A. Kameyama, T. Higashiguchi, et al., Poly-crystallized hydroxyapatite coating deposited by pulsed laser deposition method at room temperature, Appl. Surf. Sci. 248 (2005) 365-368. doi:10.1016/j.apsusc.2005.03.055.

[53] H. Zeng, W.R. Lacefield, XPS, EDX and FTIR analysis of pulsed laser deposited calcium phosphate bioceramic coatings: the effects of various process parameters, Biomaterials. 21 (2000) 23-30. doi:10.1016/S0142-9612(99)00128-3.

[54] K. Tashiro, Y. Abe, M. Kobayashi, Computer simulation of structure and ferroelectric phase transition of vinylidene fluoride copolymers (1) vdf content dependence of the crystal structure, Ferroelectrics. 171 (1995) 281-297. doi:10.1080/00150199508018440.

[55] K. Tashiro, H. Kaito, M. Kobayashi, Structural changes in ferroelectric phase transitions of vinylidene fluoride-tetrafluoroethylene copolymers: 1 . Vinylidene fluoride content dependence of the transition behaviour, Polymer (Guildf). 33 (1992) 2915-2928. doi:10.1016/0032-3861(92)90077-A.

[56] K. Tashiro, H. Kaito, M. Kobayashi, Structural changes in ferroelectric phase transitions of vinylidene fluoride-tetrafluoroethylene copolymers: 2. Normal-modes analysis of the infra-red and Raman spectra at room temperature, Polymer (Guildf). 33 (1992) 2929-2933. doi:10.1016/0032-3861(92)90078-B.

[57] T.M. Ermolinskaya, L.A. Fen'ko, A. V. Bil'dyukevich, Effect of a solvent on the solution behavior of Teflon-42 and the structure of related films, Polym. Sci. Ser. A. 50 (2008) 1065-1070. doi:10.1134/S0965545X08100076.

[58] K. Tashiro, M. Kobayashi, H. Tadokoro, Vibrational spectra and disorder-order transition of poly(vinylidene fluoride) form III, Macromolecules. 14 (1981) 17571764. doi:10.1021/ma50007a028.

[59] A. Ślósarczyk, Z. Paszkiewicz, C. Paluszkiewicz, FTIR and XRD evaluation of carbonated hydroxyapatite powders synthesized by wet methods, J. Mol. Struct. 744747 (2005) 657-661. doi:10.1016/j.molstruc.2004.11.078.

[60] A. Ślósarczyk, C. Paluszkiewicz, M. Gawlicki, Z. Paszkiewicz, The FTIR spectroscopy and QXRD studies of calcium phosphate based materials produced from the powder precursors with different ratios, Ceram. Int. 23 (1997) 297-304. doi:10.1016/S02728842(96)00016-8. 
[61] S. Baradaran, W.J. Basirun, M.R. Mahmoudian, M. Hamdi, Y. Alias, Synthesis and Characterization of Monetite Prepared Using a Sonochemical Method in a Mixed Solvent System of Water/Ethylene Glycol/N,N-Dimethylformamide, Metall. Mater. Trans. A. 44 (2013) 2331-2338. doi:10.1007/s11661-012-1595-5.

[62] D.K. Pattanayak, R. Dash, R.C. Prasad, B.T. Rao, T.R. Rama Mohan, Synthesis and sintered properties evaluation of calcium phosphate ceramics, Mater. Sci. Eng. C. 27 (2007) 684-690. doi:10.1016/j.msec.2006.06.021.

[63] R.E. Mesmer, R.R. Irani, Changes in Enthalpy During the Heating of CaHPO 4 '2H 2 O., J. Chem. Eng. Data. 8 (1963) 530-532. doi:10.1021/je60019a016.

[64] L.M. Grover, A.J. Wright, U. Gbureck, A. Bolarinwa, J. Song, Y. Liu, et al., The effect of amorphous pyrophosphate on calcium phosphate cement resorption and bone generation., Biomaterials. 34 (2013) 6631-7. doi:10.1016/j.biomaterials.2013.05.001.

[65] A.J. Lovinger, Ferroelectric transition in a copolymer of vinylidene fluoride and tetrafluoroethylene, Macromolecules. 16 (1983) 1529-1534. doi:10.1021/ma00243a021.

[66] A.J. Lovinger, G.E. Johnson, H.E. Bair, E.W. Anderson, Structural, dielectric, and thermal investigation of the Curie transition in a tetrafluoroethylene copolymer of vinylidene fluoride, J. Appl. Phys. 56 (1984) 2412. doi:10.1063/1.334303.

[67] V. V. Kochervinskii, D.A. Kiselev, M.D. Malinkovich, A.S. Pavlov, N. V. Kozlova, N.A. Shmakova, Effect of the structure of a ferroelectric vinylidene fluoridetetrafluoroethylene copolymer on the characteristics of a local piezoelectric response, Polym. Sci. Ser. A. 56 (2014) 48-62. doi:10.1134/S0965545X14010064.

[68] C.-J. Liao, F.-H. Lin, K.-S. Chen, J.-S. Sun, Thermal decomposition and reconstitution of hydroxyapatite in air atmosphere, Biomaterials. 20 (1999) 1807-1813. doi:10.1016/S0142-9612(99)00076-9.

[69] S. Okuji, H. Boldyryeva, Y. Takeda, N. Kishimoto, Characteristics of poly(vinylidene difluoride) modified by plasma-based ion implantation, Nucl. Instruments Methods Phys. Res. Sect. B Beam Interact. with Mater. Atoms. 267 (2009) 1557-1560. doi:10.1016/j.nimb.2009.01.088.

[70] C. Ribeiro, J.A. Panadero, V. Sencadas, S. Lanceros-Méndez, M.N. Tamaño, D. Moratal, et al., Fibronectin adsorption and cell response on electroactive poly(vinylidene fluoride) films., Biomed. Mater. 7 (2012) 035004. doi:10.1088/17486041/7/3/035004.

[71] A. Bigi, B. Bracci, F. Cuisinier, R. Elkaim, M. Fini, I. Mayer, et al., Human osteoblast response to pulsed laser deposited calcium phosphate coatings., Biomaterials. 26 (2005) 2381-9. doi:10.1016/j.biomaterials.2004.07.057. 